\title{
一様流中の単独平板翼の後流渦に基づく空力音源の研究*
}

\author{
佐々木 壮一苂, 林秀千人*1 \\ 児玉 好 雄*1, 深 野徹*2
}

\section{Aeroacoustic Source Caused by Wake Vortices from an Isolated Flat Plate Blade in a Uniform Flow}

\author{
Souichi SASAKI*3, Hidechito HAYASHI, \\ Yoshio KODAMA and Tohru FUKANO \\ *3 Department of Mechanical System Engincering, Nagasaki University, \\ 14 Bunkyo machi. Nagasaki shi. Nagasaki, 8528521 Japan
}

\begin{abstract}
The unsteady flow characteristics caused by the wake vortices generated from an isolated flat plate blade in a uniform flow were theoretically investigated with the discrete vortex method for elucidating the aeroacoustic source of the discrete frequency noise (DFN). We assumed that the DFN generated from the blade is originated by time fluctuation of the lift force caused by Karman vortex shedding. This calculation shows that the frequency and the intensity of velocity fluctuation in the wake can calculate accurately, and the half width of the wake is an important characteristic length to specify the periodic phenomena. The surface pressure, differentiated with respect to time, along the blade surface is closely related to the source, which gathers to the trailing edge. Then the chord wise correlation length calculated by integrating the distribution of the surface pressure data always conserved a constant value in all blades. The predicted DFN level agrees well with the experimental results.
\end{abstract}

Key Words: Vortex, Aerodynamic Acoustics. Computational Fluid Dynamics, Wake, Blade

\section{1. 序 論}

送風機の性能は所要の圧力や効率等を満足させる だけではなく，実際の運転条件下で低騒音であるこ とが重要である.このため送風機の研究開発の際は, 流体力学的特性の調査之同時に騒音特性の調査がな される(1122(3)，一般に送風機から発生する騷音は，羽 根車に流入する流れの乱れが小さい場合、翼の後流 の特性が支配的となる(4). しかし，尖機における翼 の後流は複雑な二次元流扎となっているために, 流 動状況と騷音との関係を明確にすることは難しい( ${ }^{(5)}$. そこで翼の後流渦によって生じる騒音源への影響を 究明することを目的として，空力騷音の基礎研究で は単独翼を用いた風胴実験がなさ扎ている。

深野ら(6)は，一様流中に置かれた平板翼から発生 する離散周波数騒音（以下 DFN と略す）を調査し， その中で翼表面上の音源領域となる弦長方向相関長 さに言及している. 弦長方向相関長さは, 翼弦長に

* 原高受付 2000 年 11 月 2011 .

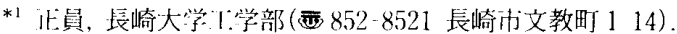

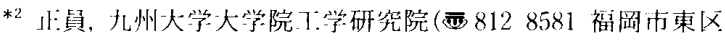
箱崎 $6-10-1)$

E-mail : souichi $a$ net.nagasaki-u.ac.jp
治う流れによって生じる空力音源の分布であるため, 実測による把握が非常に困難な特性である。この研 究によれば, 弦長方向相関長さは渦放出周波数の波 辰の $1 / 4$ の長さを基準として性質を異にする解积が なされている。しかし，その音源の性質の違いは， 測定した騒音特性の結果による実験的な根拠以外は 明らかにされていない。

一方, 計算機の著しい発展に伴い数值計算支援に 上る空力音源の性質を究明する研究(7x(x) もかなり進 歩してきた。いくかの計算法の中で，離散浮法は 流㧈の特性を循環等のポテンシャル渦に置き換える ことで計算するもので，流れの基本構造を研究する 手段として有効とされている. ポテンシャル渦によ る後流渦の性質と音源の関係を整理することができ るならば，その諸特性量を基にした空力騒音の発生 に関するエンジニアリングモデルの確立が期待でき る.このような利便性を有する計算法であるにも関 わらず離散渦法が空力騒音の音源の性質を究明する ことに心用された研究は少ない

そこで本研究では, 離散渦法による計算結果を利 用して，単独平板翼から発生する DFN の翼弦長方 向の音源の性質を明らかにする．また，この音源の 特性を基にして DFN の音压レベルの予測を試み， 
ここで明らかにした音源の性質が妥当であることを 示す.

\section{2. おもな記号}

$a_{0}$ : 音速 $\mathrm{m} / \mathrm{s}$

$b:$ スパン長さ $\mathrm{mm}$

$b_{12}:$ 後流の半值幅 $\mathrm{mm}$

$C:$ 翼弦長 $\mathrm{mm}$

$C_{L}(\mathrm{t}):$ 揚力係数

$D:$ 翼厚 $\mathrm{mm}$

$D^{*}:$ 後流の幅 $\mathrm{mm}$

$d t:$ 時間間隔 $\mathrm{sec}$

$f:$ 周波数 $\mathrm{Hz}$

$l_{c}:$ 弦長方向相関長さ $\mathrm{mm}$

$l_{s}:$ スパン方向相関長さ $\mathrm{mm}$

$M:$ 後流中の渦点数

$N:$ 翼表面上の渦点数

$N_{f}$ : カルマン渦の 1 周期中の渦点数

$p_{0}$ : 最小可聴音生 $\mathrm{Pa}$

$p^{\prime}(z)$ : 圧力の変動值 $\mathrm{Pa}$

$\dot{p}(z)$ : 代力変動の時間微分值 $\mathrm{Pa} / \mathrm{sec}$

$r$ : 音源と観測点の距離 $\mathrm{m}$

$R e:$ レイルズ数

$R\left(z_{1}, z\right)$ : 相互相関係数

$S_{c}:$ 相関面積 $\mathrm{m}^{2}$

$S P L$ : 音压レベル $\mathrm{dB}$

$S_{1}:$ ストロハル数

$U_{0}:$ 一様流の速度 $\mathrm{m} / \mathrm{sec}$

$u_{1}:$ 速度欠陥 $\mathrm{m} / \mathrm{sec}$

$u_{\mathrm{lm}}:$ 最大速度久陥 $\mathrm{m} / \mathrm{sec}$

$u^{\prime}$ : 主流方向速度変動 $\mathrm{m} / \mathrm{sec}$

$W_{D}$ : 音響パワー $\mathrm{W}$

$W(z)$ : 複素ポテンシャル $\mathrm{m}^{2} / \mathrm{sec}$

$x$ : 翼弦長力们距離 $\mathrm{mm}$

$y:$ 翼厚方向距離 $\mathrm{mm}$

$z$ : 複素平面の座標 $(z=x+\dot{y} y)$

$\Gamma_{\mathrm{j}}$ : 翼表面上の離散滑点の循環 $\mathrm{m}^{2} / \mathrm{sec}$

$\Gamma_{5}:$ 翼周りの循環 $\mathrm{m}^{2} / \mathrm{sec}$

$\Gamma_{w}$ : 後流中の渦点の循環 $\mathrm{m}^{2} / \mathrm{sec}$

$\lambda:$ 音波の波長 $\mathrm{m}$

$\rho_{0}:$ 空気密度 $\mathrm{kg} / \mathrm{m}^{3}$

一: 実効值

3. 離散渦法による流れの解析
3.1 平板嫼の形状図 1 には本離散消法で解 析した平板翼表面上の渦点の分布が示されている. 複素平面上の座標は翼の前縁を原点として翼弦長方 向距離を $x$, 翼厚方向距離を $y$ とし，これらの值は 全て複素数 $z=x+i y$ で与えられる。平板翼の前縁は翼 厚 $D$ の $1 / 2$ の半径を有し, 後縁は垂直に切り立った 形状となっている．平板翼の形状と型名との対応は 表 1 に示す通りである. なお，計算においては各物 理量を翼弦長 $C$ ，および一様流の速度 $U_{0}$ で無次元 化している.

3.2 計算方法 図 1 に示すように，平板翼は その表面上に配置した $N$ 個の渦点（その循環を $\Gamma$ とする）で近似する，この時，平板翼を近似する各 渦点の間隔は，その位置における翼の局所厚さより も狭くなるように補間されている(10)，翼の表面にあ る渦は境界層を表していると仮定し(11)，翼後縁の二 つの角 A と B にある渦点がそのまま後流中へ放出 されるとした，後流の変動は，このはく離渦からな る $M$ 個の渦点 $\left(\Gamma_{\text {wAk }}, \Gamma_{\text {wBk }}\right)$ の列で表す。この時, 流れ場の複素ポテンシャルW(z)は，時計方向の循環 $\Gamma_{\mathrm{j}}$ を正とした場合，式(1)として与えられる.

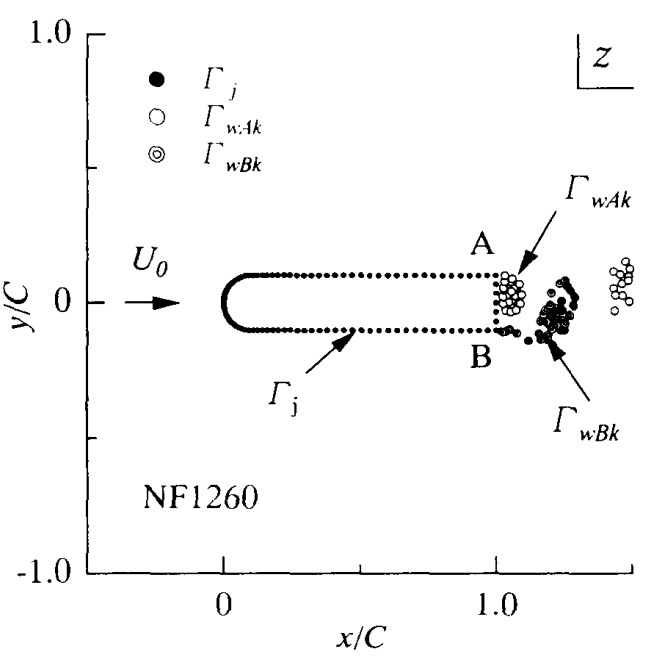

Fig.1 Distribution of vortex points

Table 1 Specifications of flat blades

\begin{tabular}{|c|c|c|c|}
\hline Blade name & $\begin{array}{c}\text { Number of } \\
\text { vortex points } \\
N\end{array}$ & Thickness & Chord \\
\cline { 1 - 3 } NF0360 & 842 & 3 & \multirow{2}{*}{6 mm } \\
\hline NF0660 & 426 & 6 & \multirow{2}{*}{60} \\
\cline { 1 - 3 } NF1260 & 218 & 12 & \\
\hline NF2460 & 114 & 24 & \\
\hline
\end{tabular}




$$
\begin{aligned}
& W(z)=U_{0} z+\frac{i}{2 \pi} \sum_{i=1}^{l} \Gamma_{j} \log \left(z-z_{j}\right) \\
& +\frac{i}{2 \pi} \sum_{k=1}^{M}\left\{\Gamma_{k: 1 k} \log \left(z-z_{k^{\prime}, 4 k}\right)+\Gamma_{n^{\prime}, B k} \log \left(z-z_{k^{\prime}, B k}\right)\right\}
\end{aligned}
$$

ここで右辺第 1 項は一様流を，第 2 項と第 3 項はそ 扎ぞ扎翼表面上の渦と後縁から放出される渦の複素 ポテンシャルを表している.

後縁 $\mathrm{A}$ とBから放出された $k$ 番目の後流の渦㷛の 時間の進行に伴う移動は, 式(2)の Lagrange のう法で 計算される。

$$
\begin{aligned}
& x_{w k}(t+d t)=x_{n k}(t)+u_{n k}(t) d t \\
& y_{n k}(t+d t)=y_{n k}(t)+v_{n k}(t) d t
\end{aligned}
$$

この時, 後流の渦放出の時間間隔 $d t$ はカルマン渦 の形成を適切に表すように，ストロハル数 $S_{t}$ の関係 を用いて，式(3)より見積もった。

$$
d t=\frac{D}{S_{t} U_{0} N_{f}}
$$

ここで, $N_{f}$ はカルマン渦の 1 周期中に含まれる渦点 の数で, 本計算では $N_{f}=20$ とした.

後流渦が後縁から放出した後, 翼表面上の渦点の 循與 $\Gamma_{\mathrm{j}}$ の強さは，式(1)を基にして流れが翼表面に 沿う条件とKelvinの定理から連立...次方程式を解く ことで修正される．後流中の非現実的な誘起速度を 抑制するための渦点の核半径や，後流中の淌点の移 動に伴う循環の減衰は, 文献(11)と同様の条件を子 えている.

複素平面上の任意の位置における共役複素速度は, 式(1)の複素ポテンシャルを $z$ で 1 階微分することで 与えら机る. 同じ位置の圧力は，共役複素速度から

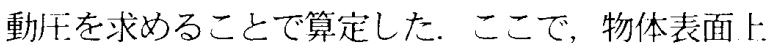

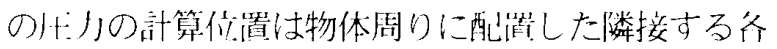
茼点の中間の位置（参照点）に統ししている。翼周 りの循環変動は翼表面上に配置した淌点の循環 $\Gamma_{\mathrm{j}}$ の総和を用いて，式(4)として定義した。

$$
\Gamma_{,}(t)=\sum_{j=1}^{N} \Gamma_{j}(t)
$$

式(4)の循環 $\Gamma$, $(t)$ を基にした揚力係数と，物体上の 非定常圧力を基にした揚力係数との違いが後述の騒 音予測の精度へ及ぼす影響は羙玨レベルに換算する と約 $1 \mathrm{~dB}$ であり，騒音予測の誤差として定めた士 3dB 以内に収まることを確認している。本研究では, 平板翼全体の循環がポテンシャル渦を用いて算定さ れる式(4)の方法を採用している.
離散消法の計算は 1 つの平板翼について 1024 回 繰り返している。この時, 総計算時閒は式(3)の时 閆間隔で兒積もると, 物体周りの循環の非定常变動 の約 30 周期分の時間に相当する.

33 実験装置実験デー夕測定のための風胴 装置はオープンチャネル形で，主流の乱れはノズル

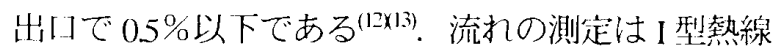
を使用し，トラバース装置で移動させながらその速 度上速度変動の分布を測定した。騒音の測定は DFN の性質が双極子型であることから，その指向 性が最も強いと考えら㧈る翼弦長方向に対して重直 方向の, 後縁から $1.0 \mathrm{~m}$ 離れた位置で行った. 尚, 翼弦長 $C$ を基準としたレイノルズ数 Re は，主流速 度 $U_{1}$ が $27.7 \mathrm{~m} / \mathrm{s}$ のとき約 $1.1 \times 10^{5}$ である。

\section{4. 計算結果および考察}

4.1 後流特性 図 2 は, 3 章で述べた離散渦法 により算定した，翼後縁から翼厚分 $(1.0 D)$ 下流の点 における後流の速度宿 $u_{1} u_{\mathrm{lm}}$ の分布を，○などの 記号で示したものである. 図中の実線は, 式(5)で 与えられる理論による $u_{1} / u_{\mathrm{Im}}$ の分布である(14).

$$
\frac{u_{1}}{u_{1 m}}=\exp \left\{-0.693\left(y / 2 b_{1.2}\right)^{2}\right\}
$$

この式(5)の分布が実験值の分布と・致することや， 羊独斗板翼の後縁から $1.0 \mathrm{D}$ 下流の点がおよそ後力 よジみ点であることは，風胴実験で既に明らかにし ている(113). 図2に見られるように，計算結果は式(5) の分布と良く一致する。 また, 後縁から $1.0 \mathrm{D}$ 下流 の位置で算定した半值幅 $2 b_{12}$ も実験値と良く一致す る（図略）。この算定位置は, 死水領域の境界に形 成される上下のせん断層が干渉し後流渦が巻きたが

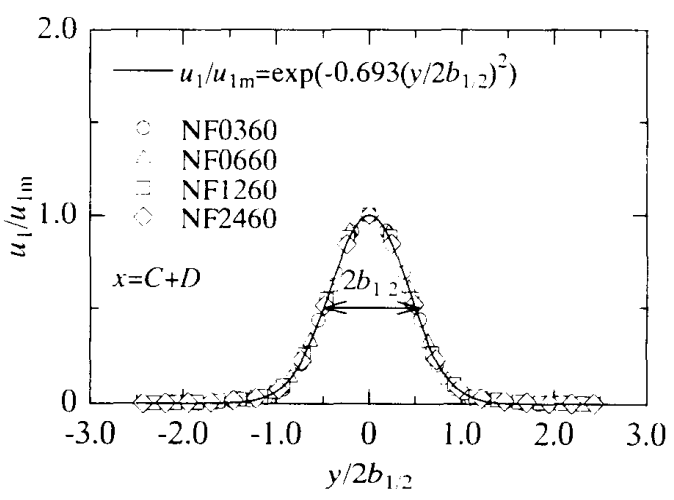

Fig.2 Distribution of velocity defects at the rear stagnation section in the wake 
り始める所で, ここでは後流の拡散があまり始まつ ていないと考えられる. また, 速度欠陥の分布は力 ルマン渦の放出に伴う後流の幅の時間平均の分布で あることから，図 2 中の $2 b_{12}$ の值は後流渦の大きさ を表す特性值であると考えられる。

図 3 の(a)と(b)にはそれぞれ, 主流方向速度変動の 強さ（変動成分の実効值） $\bar{u}^{\prime} / U_{0}$ の翼厚方向 $y / 2 b_{12}$ の分布，および流㧈方向 $x / D$ の分布の計算值を, 2 つの翼の場合を例に示している．図中の実線はいず れも実験值である. 図(a)の場合, 翼厚方向の分布や 速度変動の最大值の位置(図中の $\mathrm{A}$ 点)とレベルは 翼厚に関係なくほぼ 致する．A 点よりも内側で奏 験值が計算值より大きくなるのは，実験で使用した I 型熱線では，上下のせん断層が強く干涉する領域 で流れ方向の速度変動成分のみを測定することが出 来なかったことによる. 図(b)の分布の全体的な減 衰の傾向も両者でよく一致する.

図 4 には周波数 $f C / U_{0}$ 上後流の半值幅 $2 b_{12} / C$ （後 流の幅 $\left.D^{*} / C\right)$ の関係を示している.ここでの周波 数は，図 3(a)の A 点の位㯰における速度変動のスペ クトル分布のピーク周波数である. また，図中の実 線はストロハル数 $S_{t}$ が 0.2 であるとした場合の周波

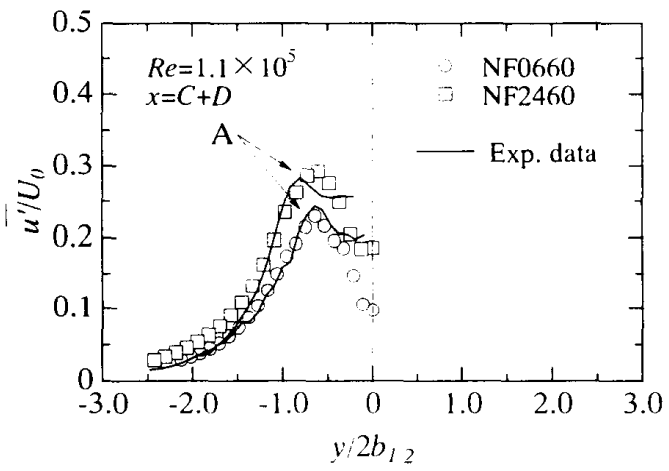

(a) Distribution in the thickness direction

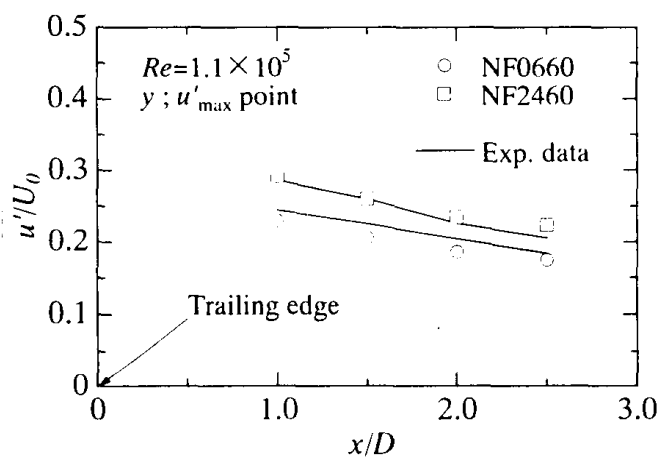

(b) Distribution in the chord direction

Fig.3 Distribution of velocity fluctuations
数 $f$ と後流の幅 $D^{*}$ の関係を示している. 計算の結果 は実線と良い相関関係にあり，代表㭕として後縁 から $1.0 D$ の位置での半值幅をとることによって， ストロハル数（無次元周波数）がほぼ一定と見なせ る. 即ち，この $2 b_{12}$ は流れの変動を代表する重要な 特性量であることが分かる. 以上のことから, 離散 渦法による計算結果は単独平板翼の近距離場後流の 変動量, 周波数, およびその分布を適切に表し得る ことが分かった。

4.2 周りの流勤特性 図 5 は, 式(4)による 翼周りの循環 $\Gamma_{\mathrm{s}} /\left(U_{0} C\right)$ の変動のスペクトル分布の 翼形状による違いを示している. 図中の破線は変動 周波数 $f$ とその循環の変動值 $\Gamma_{\mathrm{s}} /\left(U_{0} C\right)$ の積を一定と した場合の関係である. 循環の変動値のピークの值 は破線の分布にほぼ一致する。これは図 4 の結果も 勘案すると, 後流中に大きなカルマン渦が発生した 場合（ $D^{*} / C$ が大きい），翼周りには低周波の強い 循環が生じることを意味している.

次に，翼表面上の圧力変動の分布を図 6 の(a)と(b) に示す．図(a)には翼表面上の圧力変動の実効值 $\overline{p^{\prime}}(z) /\left(0.5 \rho_{i 0} U_{01}{ }^{2}\right)$ の分布を, 図(b)には压力変動の時 間微分の実効値 $\overline{\dot{p}}(z) d t /\left(0.5 \rho_{11} U_{01}{ }^{2}\right)$ の分布を示して いる. 図(a)の翼表面上の任意の点 $x / C$ における圧力

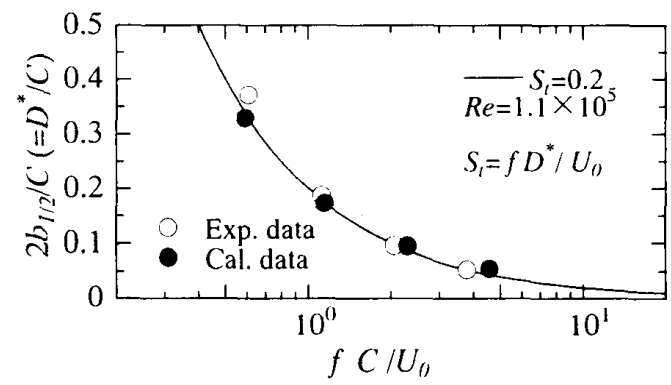

Fig.4 Relationship between the wave number and the half width of the wake

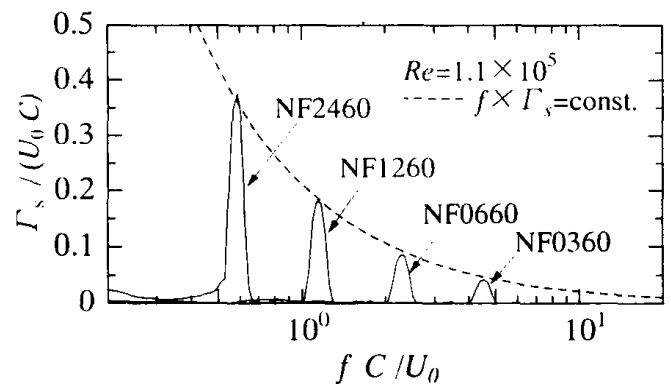

Fig.5 Spectral distribution of circulation fluctuation around the blade 
変動は，後縁から放出される渦に伴って変化する翼 表面上の渦点の分布によって誘起さ㣗る。このため 定性的には, 翼厚が大きくなる程後縁近くの強い後 流渦の循罜によって翼表面上へ強い変動を誘起し， 翼弦長に沿うト流側の压力変動の値も大きくなって いくと考えら扎る。方，図(b)の压力変動の時間 微分の分布は翼厚, 即ち, カルマン渦の大きさに依 らず定の分布になっている。こ扎は，1 周期当た りの循環の変動の時間的な変化率が, 翼厚によらず 一定になることを示すものである.

この圧力変動の分布の発生音への影響を定量的に 評価するために，弦長方向相関長さl，在定義する。 空間的な相関長さには, 相互相関係数 $R\left(z_{1}, z\right)$ の分 布に基づく積分長さが用いられることがある(15). Maruta ${ }^{(16)} ら$ はこの相関長さによる音源が, 圧力変動 の時間微分の分布と関係することを指摘している.

四 6の(b)の結果によれば，音源と考えら机る庄力変 動の时間微分の分布は翼後縁に集中しており，そ㧈 らの変動は後縁側で最も高い值を寺す，そこで翼後 縁の位置を $z_{1}$ として，弦長方向相関長さ $l_{c}$ を式(6)と して定義する。

$$
l_{c}=\frac{1}{R\left(z_{0}, z_{0}\right)} \int_{11}^{c} R\left(z_{0}, z\right) d z
$$

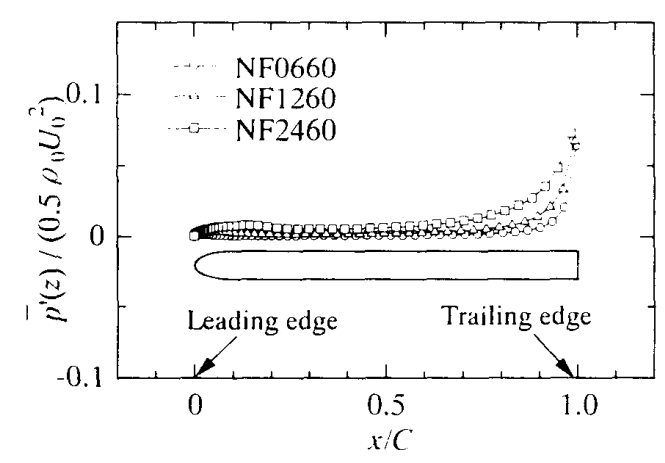

(a) Intensity of the pressure fluctuation

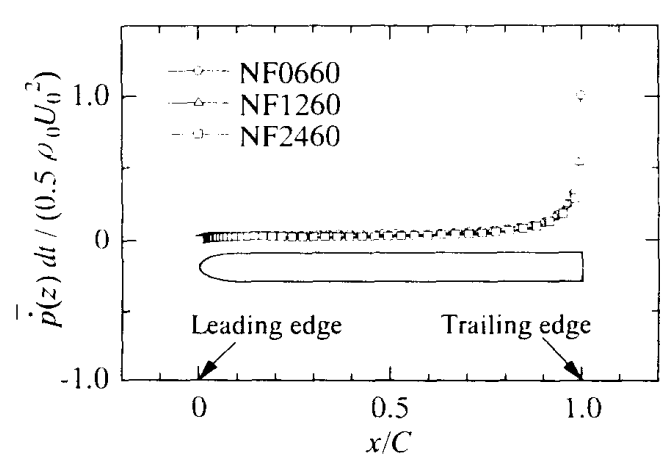

(b) Intensity of the time derivation of the pressure fluctuation

Fig.6 Characteristics of pressure on the blade surface

$$
\text { ここで }
$$

$$
R\left(z_{10}, z\right)=\frac{\overline{\dot{p}\left(z_{01}\right) \dot{p}(z)}}{\overline{\dot{p}\left(z_{01}\right)^{2}}}
$$

図 7 は弦長方向相関長さ $l_{c} / C$ の翼厚 $D / C$ による違 いを示したものである．図中の○は深野らの実験式 (の)よるる值を示して㧍りここの実験では翼厚を一定 として翼弦長を変化させて $l_{c}$ の特性を検討している. このとき， lは後流楛放出周波数の波長 $\lambda$ の $1 / 4$ の 大きさが翼弦長を超えるか否かで音圧レベルの傾向 が異なることを基にして， $l_{c}=\lambda / 4 \quad$ (if $\lambda / 4<C$ ), $l_{c}=C^{2} /(\lambda / 4) \quad$ (if $\left.\lambda / 4>C\right)$ として定義している. 文献(6) の尖験式による $l_{c}$ は，式(6)による值よりもかなり长 く見積もられる，一方，式(6)によるlの值はいずれ の翼厚でも一定となり，音源は翼後縁に集中してい ることが分かる.

43 虽音予測闵 8 に一様流中に設置された蒴 独翼力ら発生する空力音の概念闵を示している. DFN の発生は翼の後綵付近ではく離した流孔が力 ルマン渦を形成し，その渦が流出する際の翼表面上. の确所循環变動が翼表面上に压力変動を起こすこと によると考えられる，後縁から放出する渦によって 発生する音響パワー $W_{D}$ の予測式は，式(フ)が提案さ れている(6)(15).

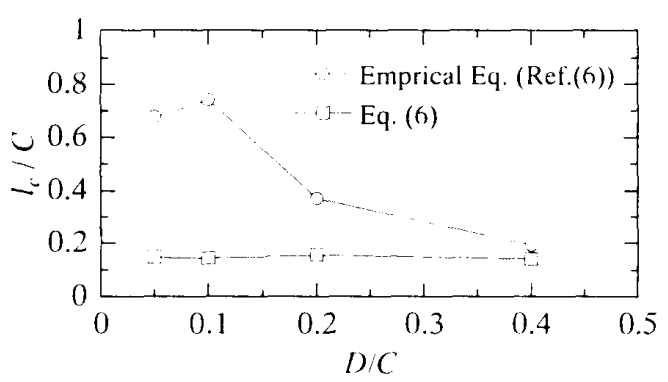

Fig.7 Variations of the chord wisc correlation length with blade thickness

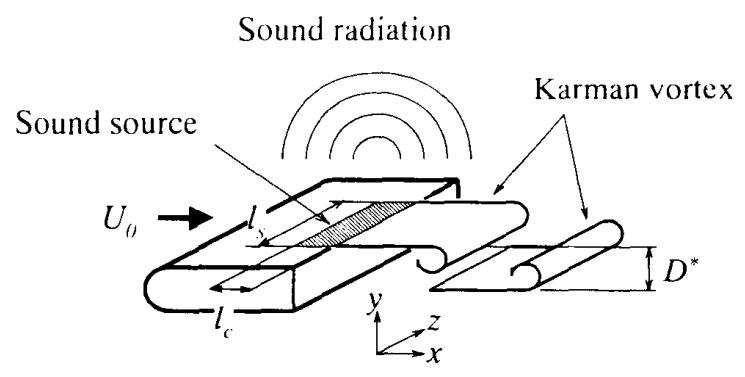

Fig.8 Physical model of aeroacoustic source of an isolated flat plate blade in a uniform flow 


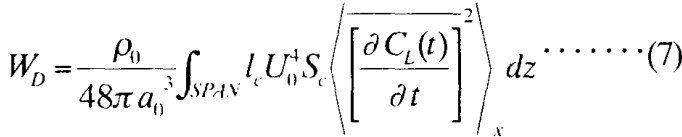

ここで， $\rho_{0}$ は空気密度， $a_{0}$ は音速， $C_{L}(t)$ は揚力係 数で，一は時間平均を示している．また， $S_{c}$ は一つ の音源の広がりを表す相関面積であり，スパン方向 相関長さ $l_{s}$ と弦長方向相関長さ $l_{c}$ の積で表される. 3 章の離散渦法は一次元計算であるために，スパン 方向相関長さ $l$ を計算で見積もることが出来ない． このスパン方向相関長さについてはいくつかの報告 (17X(1)があるが，ここでの $l_{s}$ は文献(6)による式(8)の実 験式で与えることにした。

$$
l_{s}=20 D^{*} \frac{\bar{u}^{\prime}}{U_{0}}
$$

ここで, $D^{*} は$ 後流の幅で, 本研究では後流の半值幅 $2 b_{12}$ とした。

著者らの風胴実験(12)(13)によれば，平板翼から発生

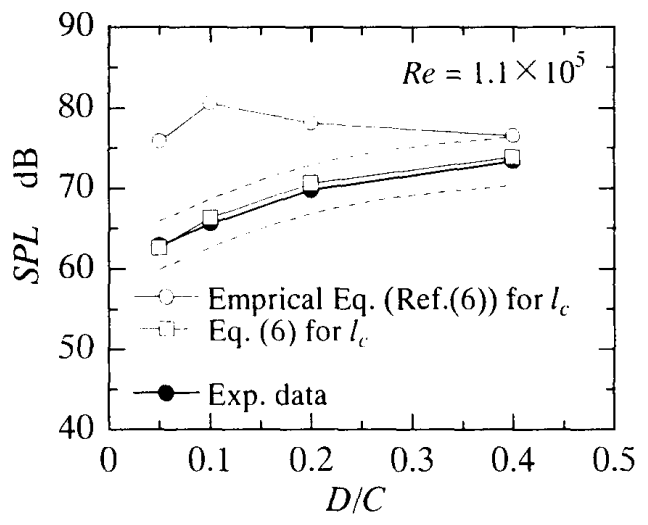

Fig.9 Variations of predicted SPL with thickness

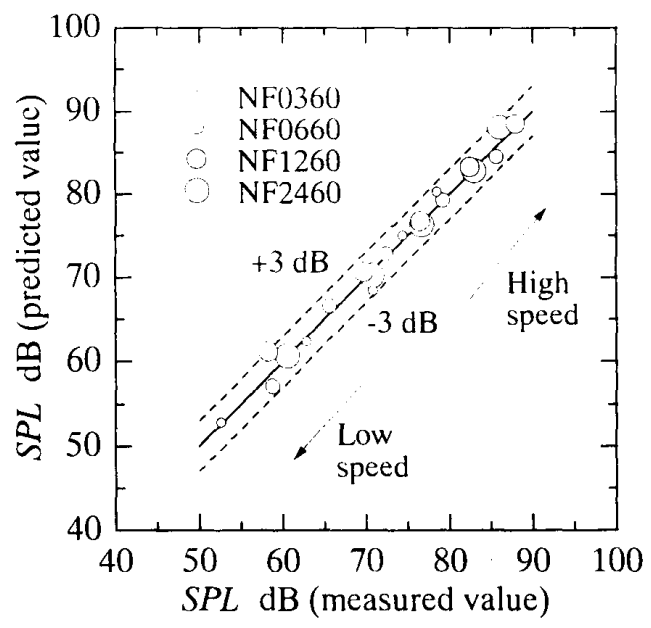

Fig.10 Comparison of the predicted SPL with the measured
する DFN は基本周波数の 1 次の騷音レベルが高く， 式(7)の揚力係数 $C_{L}(t)$ は循噮が正弦波的な変動をし ていると考えることができる．この結果より，揚力 係数 $C_{L}(t)$ は式(9)のように仮定する.

$C_{L}(t)=\frac{2 \sqrt{2} \bar{\Gamma}_{s} \sin (\omega t+\phi)}{U_{0} C}$

ここで， $\bar{\Gamma}_{s}$ は翼周りの循環の変動の実効值で, 式 (4)の循環の時開波形の実効值を用いる. この時の 音压レベル SPL は, 音響パワーと最大音压の関倸 から, 式(10)として与えられる.

$$
S P L=10 \log _{10}\left\{\frac{1}{8}\left(\frac{\rho_{01} l_{\mathrm{c}} f \bar{\Gamma}, U_{01}}{a_{0} p_{01} r C}\right)^{2} l_{\mathrm{s}} b\right\}
$$

ここで, $p_{0}$ は最小可聴音圧で $2.0 \times 10^{-5} \mathrm{~Pa}, r$ は測定 位置と音源の距離, $f$ は循環の変動周波数, $b$ は又 パン長さ $(b=230 \mathrm{~mm})$ を示している.

図 9 には音压レベル SPLの予測值の翼厚 $D / C$ によ る变化を示している. 図中のの印は風胴実験による 実測值を示しており，破線はその分布から士3dB の 呮差を示している，文献(6)の実験式による $l_{c}$ を用い た予測では，全体的に音圧レベルが高くなる，一方， 式(6)による lcを用いた場合の予測値は実測值に近い. これは，単独平板翼から発生する DFN の音源は， 圧力変動の時間微分の領域と密接に関係することを 証明するものである. 即ち, 後縁から発生する DFN の翼弦長力向の音源の相関長さは必ずしも音 の波長で整理されるものではなく，その翼厚によら ず一定に保たれることが分かる.

図 10 は DFN のピーク音压レベル SPL の実測值と, 式(10)の各パラメータに離散渦法によって求めた值 を代入した場合の予測值の関係を比較したものであ る. 図中の実線は実測值と予測值が一致する線で,

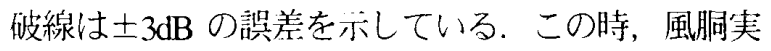
騟では主流速度を $19.2 \mathrm{~m} / \mathrm{s}$ から $55.0 \mathrm{~m} / \mathrm{s}$ まで变化させ ている. 単独平板翼から発生する DFN は, 離散渦 法の計算結果を用いることで翼形状と主流速度の違 いによらず約 $\pm 3 \mathrm{~dB}$ の精度で予測できた.

\section{5. 結 論}

離散渦法により単独平板翼周りの流動特性を計算 し, カルマン渦放出に伴う DFN の音源の性質の究 明と, その性質に基づいた騒音の予測を行った結果, 以下の結論を得た.

（1）離散渦法による非定常流れの計算で, 単独平 板翼の後縁から近距離場の後流の変動周波数, 
変動値，およびその分布を十分精度良く近似 することができる.

（2）後流の半值幅をストロハル数の代表㳡法に用 いると, 無次元周波数を一定にまとめること ができる.

(3) 弦長方向の音源分布は翼後縁に集中しており, その分布は翼厚によらず…定の長さに保たれ る.

（4）離散渦法による今问提案した偝鼠を朋いて騒 音の予測をした結果, 単独平板翼から発牛す る DFN の音压レベルを約 $\pm 3 \mathrm{~dB}$ の精度で見積 もることができた.

\section{参考文献}

（1）巟玉, 他 3 名，一重反転軸流送風機の流体力学的 特性之騒音特性に関する実験的研究（第 1 報, 軸間距離, 電動機の支持形態の影響)，機論, 60-576,B(1994-8), pp.2764-2771

（2）児玉, 他 3 名, スクロールレス遠心送風機の騒音 に関する研究（羽根前縁と日金壁面間の距離， ベルマウス出门形状およびU金すきまの影 響)，機論,63-613, B(1997-9), pp.3025-3032

(3) 新原, 他 3 名, 多翼ラジアルファンの流体力学的 特性之騒音特性に関する奏験的研究（流体力 学的特性および騒音特性に及ぼす羽根本内徍, 羽根枚数の影響)，㙨論, 62-602, B(1996-10), pp.3642-3648

(4) T. Fukano, et. al., PERIODIC VELOCITY FLUCTUATIONS IN THE NEAR WAKE OF A ROTATING FLAT-PLATE BLADE AND THEIR ROLE IN THE GENERATION OF BROADBAND NOISE, J. Sound Vib., 181-1 (1995), pp.53-70

(5) 深野, 他 3 名, 回転する単独 NACA65 翼から発生 する騒音のスペクトル密度分布の予測, 機論, 63-610, B(1997-6), pp.2047-2054
（6）深野,他 3 名，一様流中に流扎に沿って置かれた 平板から発生する離散周波数騒音に関する研 究, 機論, 51-468, B(昭 60-8), pp.2505-2512

(7) 三宅，他 2 名，機論, Large Eddy Simulation による音 源分布の解析, 59-567, B(1993-11), pp.3475-3481

(8) 古池，他 3 名，数值解析による流体音の音源分布 の解析, 機論, 62-595, B(1996-3), PP.992-998

(9) 加藤, 他 4 名, LESによる流体音の予測（第 1 献, 次元忺柱からの放射窝)，㙨論, 60-569(1994-1), pp.126-132

(10) S.M.Belostserkovsky, et. al., TWO-DIMENSIONAI SEPARATED FLOWS, CRC Press, (1993), pp.31

(11) 稲室, 足立,うず放出モデルを用いたはく離を伴

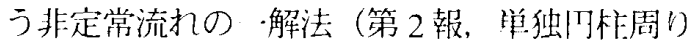
の流机）,機論, 52-476, B(昭 61-4), pp.1600-1607

(12) 林, 他 4名, 後流の周期的変動現象と後流特性量 の関係について, 長崎大学工学部研究報垲, 2647(1996), pp.137-143

（13）佐々木, 他 2 名, 離散渦法による単独翼から発生 する空力騒音の予測, 長崎大学工学部研究報告, 29-52, (1999), pp.33-41

(14) H. Schlichting, Boundary-Layer Theory, McGRAWHILL BOOK COMPANY, Six Edition, CHAPTER VIII, pp.135-148

(15) IJ.Sharland, SOURCES OF NOISE IN AXIAL FLOW FANS, J. Sound Vib., 1-3 (1964), pp.302-322

(16) Y.MARUTA, et. al., SEPARATED FLOW NOISE OF A FLAT PLATE AT LARGE ATTACK ANGLES, J. Sound Vib., 89-3 (1983), pp.335-357

(17) 横井, 亀本, 二次元的な境界層はく離流机に 潜在する初期の三次元洞構造(円柱上層流境界 層はく離の可視化観測), 機論, 57-534(1991-2), pp. $427-433$

(18) 飯田, 他 3 名, 空力音の発生機構に関する実験的 解析(第 1 報, 円柱表面厌力变動の空閶相関につ いて), 㙨論, 61-592(1995-12), pp.4371-4378 